\title{
Introduction - Stories in Science Teaching
}

\author{
STEPHEN KLASSEN \\ University of Winnipeg
}

This special issue of the journal is based on a selection of edited papers that were originally presented at the Second International Conference on Stories in Science Teaching, which took place at the Deutsches Museum in Munich, Germany in July of 2008. The conference fulfilled what can, by now, be considered a tradition of small conferences that was originally conceived in the late 1990s by Art Stinner and Juergen Teichmann. The 2008 conference brought together researchers, scholars, and educators from 12 countries to focus on stories relating to history of science and their effective use in the classroom at all levels. The conference was guided by the question "How should historical narratives be constructed, how can they be integrated into instruction, and how can they contribute effectively to student learning in science and mathematics?"

It is no secret that science education currently faces considerable challenges. As I have pointed out in my contribution to this issue, there is a fundamental incongruity between the nature of school science and scientists' science which is exacerbated by the tendency towards oversimplification and dependency on textbooks. Science instruction often suffers from a lack of context and imagination which results in a lack of student engagement. The contributors to this issue agree that one answer to this dilemma is to humanize school science through carefully selected and crafted stories, usually ones based on history of science. The side benefit of the effective usage of history as raw material is that a far more accurate, understandable, and humanistic picture of scientists' science is painted in such science instruction.

These proposed humanistic approaches to science education may, however, require a fresh look at whether the underpinning philosophies of teaching are adequate. What may be required, according to Fritz Kubli, is a philosophy of science education that takes into account classroom communication dynamics in the light of modern epistemology. Given that stories are being used, what specialized historiographical approach should guide the selection of their historical content? Peter Heering cautions that certain stories from history may, likely, be 
inappropriate to include, as they tend to mislead the reader or listener in regard to an accurate view of the nature of science.

An interesting question to consider is what a curriculum would look like if the philosophical and pedagogical approach being advocated here served as the selection criterion for the course content. Andre Dagenais answers that question by describing his experience in designing and teaching a high school physics curriculum based mainly on history and nature of science criteria. The experience has proven to be a rewarding one for both the teacher and students with the qualification that students may not be able to answer all the questions on the Advanced Placement examination since the approach necessitates the deleting of some topics that might be included in more traditional curricula.

A second answer to the question of what a curriculum could look like is provided by Wiebe and Stinner as they present an alternative approach to teaching the chemistry of gas behavior in the context of the history and nature of science. The curriculum that they present contains a series of inter-related historical vignettes that can be adapted by teachers for their own use.

In the context of the current discussion, the obvious question is what type of evidence can be provided to show that particular approaches in using stories are effective in improving student learning. Two studies included in this issue address that question and demonstrate encouraging results. In the first case, Yannis Hadzigeorgio and Vassilios Garganourakis demonstrate that a story as portrayed in a movie, can motivate students to engage in a significant learning experience and make a measurable difference in the learning outcomes. In the second case, Panos Kokkotas, Katerina Malamitsa, and Aikaterini Rizaki utilize a storytelling strategy in teaching a unit on electromagnetism and demonstrate a significant degree of student engagement in scientific inquiry.

Any discussion on using historical stories would not be complete without providing some unique or original historical cases that can, potentially, be used in the development of historical and narrative approaches. Two such cases complete this special issue. First, Stephen Klassen and Sarah Dietrich share the little-known and fascinating story of the 1909 meeting of the British Association for the Advancement of Science in Winnipeg. Finally, Martin Panusch, Rajinder Singh, and Peter Heering address the up-to-now only partially answered question, how it came to be that R.A. Millikan received the 1923 Nobel Prize in Physics. 
This special issue has, through its collection of papers, begun to answer the initial question of how historical narratives should be constructed, how they can be integrated into instruction, and how they can contribute effectively to student learning in science and mathematics.

Stephen Klassen

Guest Editor

Author's Address:

University of Winnipeg

Winnipeg, Manitoba

CANADA R3B 2E9

EMAIL: s.klassen@uwinnipeg.ca 